\title{
OS DIREITOS DE PESSOAS LGBTI EM UGANDA: REDES TRANSNACIONAIS DE ADVOCACYE A LEI ANTI-HOMOSSEXUALIDADE
}

Renata Reverendo Vidal K. Nagamine

Em princípios de 2014, o presidente de Uganda, Y. Museveni, sancionou uma lei endurecendo a repressão a determinadas práticas homossexuais e criminalizando outras, sob a justificativa de que a promoção da homossexualidade constitui uma ameaça às tradições africanas e à integridade das crianças ugandenses. Essa lei tem origem num projeto apresentado por D. Bahati em 2009, mas se atribui papel relevante em sua elaboração à atuação de grupos conservadores, notadamente líderes evangélicos norte-americanos. Em torno dos direitos de LGBTI em Uganda, formaram-se, pois, duas redes transnacionais de advocacy atuantes no país. Num primeiro momento, a rede pró-LGBTI teria conseguido forçar seu arquivamento e, depois, forçar a modificação das penas propostas, mas, ao final, não pôde impedir a sua transformação em lei.

Neste artigo, pretende-se, primeiro, apresentar a abordagem teórica de Margaret E. Keck e Kathryn Sikkink para o estudo de redes transnacionais de advocacy, com foco no modelo do "efeito bumerangue", e, depois, construir a disputa política acerca dos direitos de LGBTI em Uganda 
como um caso de disputa política entre duas redes dessa ordem, no intuito de salientar os limites, ou limitações, da abordagem teórica pelo confronto dela com um caso difícil. Um desses limites decorre de sua escolha por trabalhar com frames e consiste na negligência do sentido de figuras de linguagem empregadas na ação política, bem como do discurso em que elas aparecem. Outro limite é o papel do uso das normas jurídicas e cortes ou tribunais internacionais, que permanece indiferenciado das normas sociais e não destacado do espaço político. Para contornar o primeiro, toma-se no caminho indicado por S. Engle Merry (2006), e o segundo poderia ser teoricamente contornado lançando mão da literatura sobre mobilização legal transnacional ou, como se preferiu aqui, da abordagem proposta por U. Baxi (2006), analisando a legalização dos direitos humanos na chave política de produção-produção de política.

\section{As redes de ativismo transnacional em teoria}

Em introdução à coletânea Restructuring world politics, S. Khagram, J. V. Riker e K. Sikkink (2002b, pp. 3-23, pp. 6-8) discorrem sobre quatro formas de ação coletiva transnacional, quais sejam, as organizações não governamentais internacionais, as redes transnacionais de advocacy, as coalizões internacionais e os movimentos sociais transnacionais. Todas teriam como unidade básica a organização não governamental, que os autores definem como um grupo privado, voluntário, não lucrativo, que tem em vista influenciar publicamente uma mudança social. Essas organizações não governamentais internacionais se distinguiriam por terem membros de ao menos três países diferentes e por seus objetivos serem ou transnacionais ou internacionais. Partindo das unidades para a articulação delas se dá, primeiro, as redes de advocacy transnacional, a configuração mais informal, que se caracteriza pelo compartilhamento de valores, informações e discurso entre os atores. Em segundo lugar, 
apareceria a coalizão transnacional e, em terceiro, os movimentos sociais transnacionais, definidos como conjuntos de atores com propósito comum, vínculos transnacionais de solidariedade e capacidade de gerar mobilização social coordenada em mais de um país.

Embora o século XIX já testemunhe a formação e a eficiência de redes transnacionais de advocacy, ao ver de Keck e Sikkink elas assumem maior relevância em finais do século $\mathrm{XX}$, quando passam a interagir com maior recorrência e intensidade com Estados e organizações internacionais. Nesse período, ganham destaque, dentre essas redes, as redes transnacionais de advocacy, que se caracterizam pela centralidade de princípios e valores na sua formação (cf. Keck e Sikkink, 1998, p. 1).

Keck e Sikkink (pp. 8-9) definem essas redes como padrões de comunicação e troca voluntários, recíprocos e horizontais, dedicados a promover causas, ideias e normas em vista de mudanças que, a rigor, não interessaria diretamente a quem as defende, a se trabalhar com uma concepção estrita de interesse. Para as autoras, essas redes seriam, a um só tempo, estruturas comunicativas e espaços políticos, em que os atores negociam significados sociais, culturais, políticos da sua empresa conjunta. Por isso, Keck e Sikkink (p. 4) afirmam que as redes são estruturadas e estruturantes, conformadas pela estrutura mas também conformadoras dela, dando margem a cogitar que assim seriam superadas as dicotomias agência-estrutura e nacional-internacional.

Em conclusão de seu estudo histórico-empírico, Keck e Sikkink (pp. 12-14) afirmam que as redes transnacionais de advocacy seriam mais prováveis em situações em que os canais institucionais estariam bloqueados para equacionar o conflito entre grupos domésticos e o governo, seja por repressão, seja por inoperância; ou naquelas em que os ativistas acreditam que sua missão será facilitada pela formação de uma rede, que pode facilitar-lhes a troca de informações, 
dar visibilidade à sua causa e às suas ações, multiplicar seus canais de acesso; ou em situações em que conferências e outras formas de contato internacional formam arenas que reduzem os custos para a sua criação. Em qualquer hipótese, uma condição para a formação dessas redes seria uma abertura ou a percepção de uma abertura nas estruturas internacionais de oportunidade.

Seu papel em geral consiste em tentar influenciar atores mais poderosos, como Estados e organizações internacionais. Para isso empregam, principalmente, as táticas da (i) política de informação, pela qual gera informação útil, com agilidade e credibilidade, e a difunde nas sedes em que ela pode ter maior impacto; (ii) política simbólica, pela qual evoca símbolos, ações e histórias que tenham sentido para a audiência que pretende atingir; (iii) política de accountability, pela qual cobram os atores mais poderosos em relação a compromissos assumidos, insistindo em mostrar a distância 276 entre seu discurso e sua prática; e (iv) política de leverage, pela qual atores mais poderosos são chamados a afetar uma situação sobre a qual membros menos poderosos da rede não têm influência. Quando recorrem à política de leverage, as redes buscam, mais especificamente, uma alavanca em relação aos atores mais poderosos, a fim de serem mais efetivas do que seriam se tivessem em vista atingir as práticas estatais diretamente. Essa alavanca pode ser material, por exemplo, o dinheiro dado em ajuda humanitária, ou moral, como a exposição do alvo da ação ao escrutínio internacional (cf. Keck e Sikkink, 1998, pp. 16-24).

Para tornar mais evidentes essas interações transnacionais, Keck e Sikkink (pp. 12-13) criam um modelo, que denominam "efeito bumerangue". Nesse modelo, os atores não estatais desconsideram as fronteiras nacionais e se articulam em redes, no intuito de que núcleos dessas redes pressionem seus Estados ou organizações internacionais a pressionarem, ao seu turno, o governo ao qual 
eles não têm acesso para que esse governo atenda à sua demanda. Incrementando essa primeira construção, Khagram, Riker e Sikkink (2002, pp. 3-23; esp. p. 19) concebem o modelo espiral, conforme o qual a ação coletiva transnacional intenta promover a liberalização do regime, que acontece progressivamente, mediante a incorporação de normas internacionais, de tal modo que a cada liberalização as estruturas internas de oportunidade política se abrem, e, com isso, renovam-se os termos no cálculo para a ação coletiva.

Mas, primeiro, para que essas oportunidades sejam percebidas, elas têm de ser socialmente construídas. Dá-se a essa construção de sentido na ação coletiva, visando a participantes, opositores e observadores, o nome de framing. Parafraseando David A. Snow e Robert Benford (1998, pp. 197-217; esp. p. 198), o framing consistiria num processo pelo qual os movimentos sociais atribuem significado e interpretam acontecimentos relevantes, no intuito de mobilizar potenciais aderentes e constituintes, angariar o apoio de espectadores e desmobilizar antagonistas. Com esses propósitos gerais, tentando criar, recriar, deslocar sentido, são empregados os frames, quadros de significado embalados numa retórica que o beneficie (Cf. Khagram, Riker e Sikkink, 2002, pp. 3-23; esp. pp. 12-13).

Falando mais especificamente, cabe ao frame diagnosticar um aspecto problemático da vida social a ser alterado e atribuir responsabilidade por ele; propor uma solução para esse problema e identificar táticas, estratégias, alvos para a ação; e motivar o engajamento na ação coletiva corretiva, haja vista que o acordo acerca do diagnóstico e da solução proposta não levam diretamente a ela. Suas duas primeiras tarefas diriam respeito à mobilização de um consenso e a terceira daria o impulso para a participação propriamente dita, mas um frame tende a ter tanto mais sucesso quanto mais as integra e quanto mais direta for a relação de causa- 
lidade estabelecida (cf. Snow e Benford, 1998, pp. 197-217; esp. pp. 199-202).

Outros fatores, além desses, concorrem para o sucesso, ou, nos termos da própria teoria, para a ressonância de um frame. No que se refere aos constrangimentos dos sistemas de crenças a que eles se ligam, contariam a centralidade ou saliência da ideia que ele invoca em relação às demais; seu alcance do elemento ou os domínios da vida que abrange; e o grau de inter-relação entre os vários elementos ideacionais num sistema de crenças. Já no que se refere aos constrangimentos fenomenológicos, contariam a sua credibilidade de uma perspectiva empírica, a comensurabilidade da experiência a que ele remete, ou o anteparo pelo qual ela é filtrada, e sua fidelidade narrativa, sua sintonia com as histórias, os mitos, o folclore que compõem a tradição e continuam a informar o presente (cf. Snow e Benford, 1998, pp. 197-217; esp. pp. 205-10).

278 Tal abordagem, calcada na literatura de redes de advocacy e, dentro dela, de frames, seria bem-sucedida no que parece ser um propósito implícito seu, i.e., dar conta de que, como disse Tarrow (1996, pp. 41-61; esp. pp. 58-59), os movimentos sociais não só aproveitam as oportunidades, como também as criam, seja atuando por estratégia e por princípios, seja mobilizando recursos e produzindo sentido. Eles podem criá-las ampliando as oportunidades do próprio grupo ou ampliando as oportunidades para demais grupos de protesto, quando colocam em pauta assuntos com os quais outros grupos se identificam e quando mostram a utilidade da ação coletiva. O impacto da ação das redes pode se dar, de resto, em diversos estágios, com benefícios progressivos: (i) na criação de um problema e formulação de agenda, quando atraem atenção para um problema que não fora debatido publicamente; (ii) nas posições discursivas de Estados e organizações internacionais, quando tentam arrancar-lhes declarações em que eles de alguma forma se comprometam com a sua causa; 
(iii) em procedimentos institucionais, que são importantes porque podem aumentar as oportunidades na estrutura; (iv) na mudança de políticas; e (v) no comportamento estatal (cf. Keck e Sikkink, 1998, p. 25).

Mas a eficácia das redes de advocacy também depende de determinadas características dos atores e dos problemas que elas buscam equacionar. No que se refere aos atores, as redes têm de ser densas e incluir ativistas tanto dos países-alvos, que conferem credibilidade à informação e legitimidade à atividade da rede, como de países que tenham uma alavanca institucional em relação a ele, ao passo que os alvos das redes têm de ter algum tipo de vulnerabilidade - material ou moral - a incentivos ou sanções. Quanto aos problemas que buscam equacionar, teriam maior ressonância transnacional as situações que envolvem dano físico a indivíduos vulneráveis e igualdade de oportunidade perante a lei (cf. Keck e Sikkink, 1998, p. 29). Essa vulnerabilidade dos indivíduos e a desigualdade têm de ser, de todo modo, construídas, o que, para Keck e Sikkink, tem sido feito desde os anos 1970 pelo frame "direitos humanos".

No que segue, se procurará mostrar, neste artigo, a formação de uma rede transnacional de advocacy em prol dos direitos de pessoas LGBTI ugandenses, identificando suas principais estratégias, ações, quadros e a mudança de escala na mobilização, elemento fundamental no modelo do "efeito bumerangue”, concebido por Keck e Sikkink. Também se procurará mostrar a disputa entre essa rede em prol de pessoas LGBTI ugandenses e uma rede formada por líderes religiosos norte-americanos, ONGs e associações internacionais, igrejas pentecostais locais reunidas sob a Igreja Anglicana, com aparente largo apoio da população local e penetração no governo. Na identificação dessa disputa, serão indicados alguns constrangimentos atuantes sobre as redes e serão realçados os quadros mobilizados por ambos os lados e o recurso da rede em prol de LGBTI às cortes. 


\section{As redes transnacionais LGBTI e anti-LGBTI em Uganda}

\section{0 ativismo LGBTI em Uganda e a formação de uma rede transnacional}

Notícias repercutindo episódios de homofobia em Uganda se tornaram mais recorrentes na mídia internacional na passagem dos anos 1990 para os anos 2000. De início, elas apareciam em meio a notícias de episódios semelhantes em outros países africanos e declarações de líderes regionais reputando a homossexualidade a um artigo "colonial", o ativismo LGBTI a um "produto do imperialismo ocidental", e os homossexuais, "não africanos", "não bíblicos" (cf. Uwihanganye, 2010) ou, para o Zimbábue Robert Mugabe, "piores que cães e porcos", sem direitos civis no país (cf. McNeil Jr., 1998). Essas notícias eram dadas, ademais, por ONGs como a Anistia Internacional, a Human Rigths Watch e a International Gay and Lesbian Human Rights 280 Commission (IGLHRC), que as recebiam de membros de organizações não governamentais locais.

Parte dessas organizações locais atuava na prevenção do HIV/Aids, uma epidemia na África, em particular em Uganda, a demandar o aporte de recursos estrangeiros. Outras se dedicavam à promoção dos direitos humanos, aproveitando a abertura dada pela Constituição de 1995 e por tratados internacionais de direitos humanos ratificados por Uganda. Mas a formação de organizações não governamentais para reivindicar direitos da minoria LGBTI, em seus próprios quadros, a "não discriminação" e a "igualdade legal e social" para LGBTI, seria tardia, tendo começado na primeira metade dos anos 2000, com a formação da Freedom and Roam Uganda, em 2003, o Icebreaks Uganda, em 2004, e a Sexual Minorities Uganda (SMUG), a abrigar essas e outras ONGs, também em 2004. De acordo com essas ONGs, sua criação decorre de abusos sofridos pela minoria LGBTI, e uma possível razão para o seu aparecimento relativamente 
tardio possa ser o fato de a prática de atos homossexuais ser considerada crime em Uganda.

Os informes da Anistia Internacional, da Human Rights Watch e da International Gay and Lesbian Human Rights Commission (IGLHRC) mostram que, nessa mesma época, começam a se precipitar em Uganda episódios de detenção e tortura de pessoas LGBTI em razão da sua orientação sexual, da sua identidade sexual ou da sua atuação pelo reconhecimento de direitos a LGBTI $^{1}$. Quando a IGLHRC torna pública, em informe de 27 de julho de $2005^{2}$, uma nota da SMUG condenando uma busca sem mandato na residência do ativista Victor Mukasa e a detenção de Yvonne Oyo, tem-se enfim uma mostra da mudança de escala do movimento, com o que configuraria uma rede transnacional. Pode-se pensar, nesse caso, que a falta de canais de diálogo com o governo, logo, de meios para influenciá-lo e a oportunidade de diálogo com ONGs internacionais teriam, pois, incentivado as organizações não governamentais de Uganda a recorrerem a organizações com sede em outros Estados e projeção internacional para ter acesso aos meios que lhes faltavam para atingir seu alvo, remontando ao "efeito bumerangue", concebido por Keck e Sikkink.

Essa escalada das ONGs ugandenses ao ativismo transnacional pelos direitos de LGBTI não importou, de resto,

\footnotetext{
${ }^{1}$ Em 29 de janeiro de 2004, por exemplo, a IGLHRC relata a escalada na intimidação e perseguição de ativistas em Uganda, que teria sido deflagrada pela punição a um programa de rádio por ofender a moralidade pública com um debate sobre a discriminação de gays e lésbicas nos programas para a prevenção do HIV/Aids, a que ainda teriam seguido assaltos à segurança de pessoas que se supunha serem LGBTI, e a publicação de uma lista com o nome de vários deles no semanário The Xtreme: "Uganda: Persecution of lesbians and gay men intensifies”. Disponível em: <http://www.iglhrc.org/cgi-bin/iowa/article/pressroom/ pressrelease/517.html $>$. Acesso em: 3 jul. 2014.

2 "Uganda: Press release from SMUG (Sexual Minorities Uganda)". Pesquisa realizada em 2012 em: <http://www.iglhrc.org/cgi-bin/iowa/home/index.html>. [Página não mais disponível em 3 jul. 2014.]
} 
no abandono do ativismo no plano local. Em conformidade com o modelo, o ativismo local mostrou-se, com efeito, essencial para o sucesso da rede. O episódio condenado na nota da SMUG deu origem a um processo que chegou à Alta Corte de Uganda em 2008. Em sua apreciação, a Corte acolheu a versão dos fatos dada por Mukasa e Oyo - de que oficiais entraram na casa de Mukasa, apreenderam bens relacionados com suas atividades como ativista de direitos humanos, levaram Oyo e a humilharam na delegacia -, e julgou que o direito de Mukasa à privacidade foi violado pela ingerência em sua residência, enquanto o direito de Oyo à igual proteção da lei foi violado por sua detenção arbitrária pela polícia, na noite de 20 de julho de $2005^{3}$. Na sentença, a Alta Corte dissocia o reconhecimento desses direitos de uma apreciação positiva da homossexualidade, mas, logicamente, ao reconhecer o direito de Mukasa e Oyo à privacidade e à igual proteção da lei, acaba por reconhe282 cê-los como sujeitos de direito, contrapondo-se aos esforços de desumanização de pessoas LGBTI empreendidos pelo governo de Uganda. Esse desfecho daria a ver, entre outras coisas, que a mobilização legal pode consistir numa ação genuinamente política para atores não estatais, quando o espaço público lhes é negado seja por política estatal, seja por condescendência do Estado com a discriminação empreendida pela sociedade ${ }^{4}$.

\footnotetext{
${ }^{3}$ Ver Ação "Mukasa and Another v. Attorney-General (2008)", AHRLR 248 (UgHC, 2008).

${ }^{4}$ Segundo dados do Pew Research Center, "The Pew Global Attitudes Project: World publics welcome global trade - but not immigration" (Washington, Oct. 4, 2007), parece ser esse o caso de Uganda, tendo em conta que, em 2007, $87 \%$ dos ugandenses entendiam que ser moral implica acreditar em Deus, $46 \%$ entendiam que Estado e igreja deviam ser separados - contra $62 \%$ em 2002 -, e $96 \%$ consideravam que a homossexualidade devia ser rejeitada. $\mathrm{O}$ argumento parece mais consistente quando se tem em conta o censo de 2002, do Bureau of Statistics de Uganda, segundo o qual $44,5 \%$ da população ugandense professam a religião católica, $39,2 \%$ a anglicana, $10,5 \%$ a muçulmana, $1,7 \%$ outras religiões cristãs e $4 \%$ outras religiões não cristãs, o que perfaz uma população praticamente toda religiosa, que condena a homossexualidade de modo quase unânime. De resto, é claro que
} 


\section{A disputa da rede pró-LGBTI com a rede cristã anti-LGBTI em Uganda}

No curso dos anos, principalmente de meados dos anos 2000 em diante, passou-se a indicar como causa da homofobia em Uganda a ação de igrejas e líderes religiosos ou, mais especificamente, a ação das igrejas de denominação anglicana. Em estudo do reverendo zambiano Kapya Kaoma (2009, p. 7), a Conferência Lambeth de 1998 foi considerada um ponto de inflexão no entendimento da sexualidade pelas igrejas no geral e um marco no avanço da África para a linha de frente na oposição LGBTI. Mais do que isso, a inserção do tema na pauta da conferência foi uma tática usada para forçar um debate que se sabia dividiria a Comunhão Anglicana. Kaoma (2009, pp. 19-20) afirma que ela foi escolhida em conjunto por igrejas africanas e igrejas norte-americanas, com benefícios de parte a parte: as últimas ganhariam força para fazer oposição a grupos progressivos e majoritários, mais abertos às reivindicações LGBTI; as primeiras teriam acesso a público e recursos de outro modo inacessíveis para elas.

Essa associação transcontinental se tornará mais estreita e possibilitará a circulação de recursos financeiros e logísticos, pessoas e discursos na rede se intensificarão. Para além das afinidades teológicas, esse estreitamento seria mediado por figuras como o bispo norte-americano Rick Warren, amigo da primeira-dama e congressista em Uganda, Janet Kataaha Museveni (cf. Kaoma, 2009, p. iv), o qual tinha posições moderadas sobre o tema nos Estados Unidos, mas,

a relevância desses dados depende, no entanto, da importância da religião para a população, que não se pode saber pelo censo e, por mais tentador que seja, também não pode ser medida pela relação entre a crença em Deus e a moralidade, que põe em questão, ao seu turno, a importância da moralidade. Mas, então, outra pesquisa efetuada em 2010 pelo Pew Research Center, "Tolerance and tension: Islam and Christianity in Sub-Saharan Africa" (Washington, April 15, 2010) obteve que a religião é muito importante na vida de $86 \%$ de uma população $86 \%$ cristã e $13 \%$ muçulmana, números bastante próximos do censo. 
em solo africano, declarou que "a homossexualidade é um modo de vida não natural e, portanto, não é um direito humano", ao falar em apoio aos bispos ugandenses que boicotariam a Conferência Lambeth de $2008^{5}$. Menos dúbio ainda que Warren, seria atuante nessa rede contra-LGBTI o bispo norte-americano Scott Lively, autor de Pink Swastika (1995) e Redeeming the rainbow: a Christian response to the "gay" agenda (2009), bem como Caleb Lee Brundidge, conhecido por afirmar poder curar gays, e Lou Engle, fundador e diretor da TheCall, que tem sede em Kansas City, mas atua em escala internacional, especialmente em Uganda, para onde rumariam crescentemente seus missionários.

Lively, o bispo norte-americano Don Schmierer, da Exodus Internacional, e Lee Brundidge serão convidados de honra de Stephen Langa, diretor-executivo da Family Life Network, em seminário realizado pela organização em março de 2009, para "expor a verdade por trás da homossexualidade e da 284 agenda homossexual” em Uganda. O seminário respondia à decisão no caso Mukasa e Oyo, em que a Alta Corte de Uganda estabelecera limites às ações do governo em relação a pessoas LGBTI: tratou-se, então, de alertar os fiéis ugandenses em relação ao recrutamento para a homossexualidade em curso nas escolas, a sua inclinação à pedofilia, ao abuso sexual, e ao perigo que o ativismo em prol de direitos de pessoas LGBTI representava, do que eram exemplos os próprios Estados Unidos. Parlamentares e políticos, como o ministro da Informação e da Comunicação e, depois, da Ética e da Integração, James Buturo, prestigiaram o seminário, e, por ocasião dele, os bispos norte-americanos ainda falaram em escolas e universidades em Uganda.

Em fins do mesmo ano, o parlamentar Hon David

\footnotetext{
${ }^{5}$ No original: "homosexuality is not a natural way of life and thus not a human right". Publicado em "Gay row - U.S. pastor supports country on boycott", The Monitor, 29 March 2008. Disponível em: <http://allafrica.com/stories/ 200803281265.html>. Acesso em: 3 jul. 2014.
} 
Bahati propôs um projeto de lei anti-homossexualidade ao Parlamento de Uganda, com o intuito declarado de defender os valores familiares e proteger as crianças (cf. Edwards, 2010). O projeto torna mais precisa e endurece a regulação da homossexualidade, criando os tipos penais "ofensa da homossexualidade", "homossexualidade agravada" e "tentativa de praticar homossexualidade", sendo agravada a homossexualidade em série, ou praticada com menor de dezoito anos, ou praticada por pessoa com $\mathrm{HIV}^{6}$. Cria, ademais, a obrigação de denunciar supostos gays, lésbicas, bissexuais, transexuais, transgêneros, e os tipos penais "ajudar e encorajar a homossexualidade" e "promoção da homossexualidade", pretendendo-se assim enquadrar toda ação e organização que contemplasse $\mathrm{LGBTI}^{7}$. Para completar, pune a

${ }^{6}$ Itens 2, 3 e 4 do projeto (Bahati, 2009): "2. a ofensa de homossexualidade. (1) A pessoa comete a ofensa de homossexualidade se (a) ela penetra o ânus ou boca de outra pessoa do mesmo sexo com seu pênis ou qualquer outro aparelho; (b) ele ou ela usa qualquer outro objeto ou aparelho sexual para penetrar ou estimular órgão sexual de uma pessoa do mesmo sexo; (c) ele ou ela toca outra pessoa com a intenção de cometer o ato de sexualidade. (2) Uma pessoa que comete uma ofensa sob esta seção deverá ser responsabilizada com condenação a prisão perpétua. 3 . homossexualidade agravada. (1) Uma pessoa comete a ofensa de homossexualidade agravada quando (a) a pessoa com a qual a ofensa é cometida tem menos de 18 anos; (b) o ofensor é uma pessoa vivendo com HIV; (c) o ofensor é um parente ou guardião da pessoa contra a qual a ofensa é cometida; (d) o ofensor é uma pessoa com autoridade sobre a pessoa contra a qual a ofensa é cometida; (e) a vítima da ofensa é uma pessoa com deficiência; (f) o ofensor é um ofensor em série; o ofensor aplica, administra ou facilita usar-se por algum homem ou mulher alguma droga, matéria ou coisa com a intenção de entorpecer ou dominar ele ou ela até lá, de modo a aí permitir qualquer pessoa ter conexão carnal ilegal com qualquer pessoa do mesmo sexo. (2) Uma pessoa que comete a ofensa ilegal de homossexualidade agravada deve estar sujeita à condenação por morte. (3) Uma pessoa que é acusada da ofensa sob esta seção deve submeter-se a exame médico para saber da sua situação no que se refere ao HIV. 4. tentativa de cometer a homossexualidade. (1) Uma pessoa que tenta cometer a ofensa de homossexualidade comete um crime e está sujeita à condenação de prisão por sete anos. (2) Uma pessoa que tenta cometer a ofensa de homossexualidade agravada comete uma ofensa e está sujeita à condenação de prisão perpétua" (tradução da autora).

${ }^{7} \mathrm{O}$ item 7 do projeto determina que: "ajudar e incitar à homossexualidade. Uma pessoa que ajuda, incita, aconselha ou procura outra para engajar-se em atos de homossexualidade comete uma ofensa e está sujeita à condenação de prisão por sete anos". Já o item 13 dispõe sobre a "promoção da homossexualidade" e dispõe 
"ofensa da homossexualidade" com a prisão perpétua e sua forma agravada com a pena de morte. Foi esse, por sinal, um dos pontos mais polêmicos do projeto, ao lado da criminalização do ativismo LGBTI, e da extraterritorialidade da jurisdição de Uganda $^{8}$, prevista apenas para os crimes de traição e terrorismo.

O projeto de Bahati teve imediata e estrondosa repercussão internacional. Na época, o presidente Barack Obama era, ao seu turno, cobrado por compromissos de campanha assumidos para com o movimento LGBT norte-americano (cf. Gay Stolberg, 2009), em especial, a ampliação da definição dos crimes de ódio para incluir a "orientação sexual” como motivação para eles (cf. Hulse, 2009); a revogação do “don't ask, don't tell” (DADT) nas forças armadas, que impedia militares norte-americanos de assumir sua homoafetividade ${ }^{9}$; e a revogação do Defense of Marriage Act (DOMA), que define o casamento como 286 uma união entre homem e mulher (cf. Seelye, 2010). Na sociedade norte-americana, a resistência à agenda LGBT tinha diminuído ao longo dos anos $2000^{10}$ e tanto o DADT

que "Uma pessoa que - (a) participa na produção, marketing, disseminação, publicação de material pornográfico com o propósito de promover a homossexualidade; (b) doa fundos ou patrocina a homossexualidade ou outras atividades relacionadas; (c) oferece dependências ou outras rendas fixas ou móveis para propósitos relacionados com a homossexualidade ou para promovê-la; (d) usa aparelhos eletrônicos, o que inclui internet, filmes, celulares, para propósitos de homossexualidade ou promover a homossexualidade; e (e) que age como cúmplice ou tenta promover ou de qualquer modo incita a homossexualidade e práticas relacionadas; comete uma ofensa e está sujeita a uma multa de 5 mil em moeda corrente, prisão de um mínimo de cinco anos e um máximo de sete anos ou ambas, multa e prisão. (2) Se o ofensor é uma corporação ou um negócio ou uma associação ou uma organização não governamental, na condenação seu certificado de registro deve ser cancelado e o diretor ou proprietário ou quem o promove deve estar sujeito à condenação de prisão por sete anos" (Bahati, 2009; tradução da autora) . ${ }^{8}$ Cf. item 16 do projeto (Bahati, 2009).

${ }^{9}$ Ler a respeito, no New York Times: "Obama pledges again to end "don't ask, don't tell”, Oct. 11, 2009; "Ending don't ask, don't tell”, Editorial, Jan. 29, 2010; E. Bumiller, "Forces pushing Obama on 'Don't ask, don't tell'”, Feb. 1, 2010; "Equality in the military", Editorial, Feb. 3, 2010.

${ }^{10}$ Nesse sentido, ver Nagourney (2009) e pesquisa Gallup de maio de 2011 sobre 
como o DOMA eram politicamente condenados por fazerem de alguns cidadãos norte-americanos "cidadãos de segunda classe" e eram juridicamente contestados com fundamento na "igual proteção perante a lei" mostra de sensibilidade a tudo isso, no encontro anual National Prayer Breakfast, em fevereiro de 2010, o presidente Barack Obama manifestou sua repulsa ao projeto e o qualificou de odioso ${ }^{12}$.

Em março de 2010, o próprio presidente Museveni comentou a pressão dos países do Hemisfério Norte sobre Uganda por causa do projeto de lei, ao relatar o Commonwealth Heads of Government Meeting (CHOGM) ao Parlamento:

O primeiro-ministro do Canadá veio me encontrar e sobre o que ele falou? Gays. O primeiro-ministro Gordon Brown veio me encontrar e sobre o que ele falou? Gays. A senhora Clinton [secretária de Estado dos Estados Unidos] me rodeou. Sobre o que ela falou? Gays. Houve uma passeata de 300.000 gays em Nova Iorque. Agora, eu quero desafiar vocês, membros do Parlamento, quantos de vocês, além de mim, já presenciaram uma passeata de 300.000 pessoas? $^{13}$

\footnotetext{
direitos de gays e lésbicas, disponível em: <http://www.gallup.com/poll/1651/ gay-lesbian-rights.aspx>. Acesso em: 10 dez. 2012.

${ }^{11}$ Ler a respeito, publicado no New York Times: "Ending 'don't ask, don't tell'”, Jan. 29, 2010; Rich (2009); e Seelye (2010).

${ }^{12}$ Ver mais em: "President of the United States, Remarks by the President at the National Prayer Breakfast", Feb. 4, 2010. Disponível em: <http://www.whitehouse. gov/the-press-office/remarks-president-national-prayer-breakfast $>$. Acesso em: 17 dez. 2012.

${ }^{13}$ No original: "The Prime Minister of Canada came to see me and what was he talking about? Gays. Prime Minister Gordon Brown came to see me and what was he talking about? Gays. Mrs. Clinton [US Secretary of State] rang me. What was she talking about? Gays. There was a rally in New York of 300,000 homosexuals. Now, I would want to challenge you members of Parliament, how many of you, other than me, have had a rally of 300,000 people?" (Miwambo, 2010).
} 
O ministro de Estado do Reino Unido para a África, ao seu turno, contou a mesma história, em outras circunstâncias e de outra perspectiva, reforçando a impressão de que o Encontro dos Chefes de Governo dos Países da Commonwealth teria sido uma oportunidade extraordinária em relação à rotina das trocas diplomáticas para chefes de governo pressionarem Uganda a respeito do polêmico projeto.

Do mesmo modo, eu coloquei o assunto em pauta com o ministro para Assuntos Exteriores de Uganda, Sam Kutesa, também no CHOGM. O Alto Comissário do Reino Unido em Kampala aproveita toda oportunidade para tratar do assunto com ministros de Uganda. Nós também fizemos lobby junto à UE, e a Suécia, que ocupava a Presidência da UE em Kampala, tomou a frente da manobra da UE junto ao ministro ugandense para Assuntos Exteriores em 288 dezembro ${ }^{14}$.

Dada a importância dos recursos estrangeiros para o governo de Uganda, notadamente norte-americanos ${ }^{15}$, bri-

\footnotetext{
${ }^{14}$ No original: "Likewise, I raised the issue with Uganda's minister for Foreign Affairs, Sam Kutesa, also at CHOGM. The UK High Commissioner in Kampala takes every appropriate opportunity to engage Ugandan Ministers on the issue". / "We have also lobbied through the EU, Sweden, who held the EU Presidency in Uganda, led EU demarche to Ugandan Foreign Ministry in December" (Miwambo, 2010).

${ }^{15}$ No ano fiscal de 2008, os Estados Unidos destinaram 431.225 milhões de dólares a Uganda pela USAID, sendo 316.082 milhões para investimento em pessoas; no ano fiscal de 2009, esses números foram de 416.053 milhões e 328.430 , respectivamente; no ano de 2010, foram de 456.819 milhões e 388.084 milhões; no ano de 2011, de 480.302 milhões e 404.684 milhões. Dados disponíveis em: <http://www.usaid.gov/locations/sub-saharan_africa/countries/uganda/ uganda_fs.pdf $>$. Acesso em: 24 jan. 2012. Para se avaliar melhor o que isso representa, o produto interno bruto de Uganda em 2009 foi de 17 bilhões e 110 milhões de dólares. Dado disponível em: <http://data.un.org/CountryProfile. aspx? crName=Uganda\#Economic $>$. Acesso em: 24 jan. 2012.
} 
tânicos ${ }^{16}$, da União Europeia ${ }^{17}$, e do seu interesse em manter a reputação de modelo para os demais países africanos no combate ao HIV/Aids, pode-se pensar que a paralisação do trâmite do projeto no Parlamento em 2010 de fato decorra da pressão da comunidade internacional.

\section{O duvidoso sucesso da rede pró-LGBTI: da Alta Corte de Uganda à Corte distrital do Distrito de Massachusetts}

O sucesso da rede pró-LGBTI em barrar a tramitação do projeto de lei no Parlamento de Uganda decerto não inibiu seus partidários. Em outubro de 2010, um tabloide local, o Rolling Stone, publica uma lista de supostos homossexuais, tendo por manchete o anúncio de 100 "top homos" ugandenses, com nome e endereço, e o chamado para enforcá-los ${ }^{18}$. Imediatamente, os ativistas Kasha Jaqueline, David Kato e Onziema Patience acionaram a Alta Corte de Uganda contra o jornal, pedindo que ele fosse impedido de publicar informações dessa ordem. Em decisão de 31 de dezembro de 2010, concedendo o pedido dos requerentes, a Corte (i) afirma que o processo não era sobre a homossexualidade dos autores, mas sobre seu direito à vida e à privacidade, sobre direitos fundamentais, concedendo o pedido; (ii) não se furtando a rebater o argumento do advogado de defesa de que os autores não

\footnotetext{
${ }^{16} \mathrm{O}$ Reino Unido, segundo maior doador bilateral, alocou sozinho mais de 60 milhões para Uganda em 2009, mais de 90 milhões em 2010 e cerca de 80 milhões em 2011, não estritamente para fins humanitários. Dados disponíveis em: <http:// www.dfid.gov.uk/where-we-work/africa-eastern-southern/uganda/>. Acesso em: 24 jan. 2012.

${ }^{17}$ A Comissão Europeia alocou 158 milhões de euros para ajuda humanitária em Uganda entre 2002 e 2011, sendo mais de 30 milhões em 2008, mais de 25 milhões em 2009, pouco mais de 10 milhões em 2010 e menos de 5 milhões em 2011. Esses dados estão disponíveis no site da Comissão Europeia: <http://ec.europa.eu/ echo/files/aid/countries/uganda_brochure_en.pdf>. Acesso em: 24 jan. 2012.

${ }^{18}$ Segundo informa a SMUG em inicial junto à corte distrital do Distrito de Massachusetts e acolhe a corte, o jornal, ou tabloide, era editado por estudantes da universidade ugandense Makerere e ligados a Martin Ssempa, que aí pregava contra a prática da homossexualidade, contra pessoas LGBTI e seu ativismo.
} 
seriam idôneos nem teriam direito a igual tratamento por ser a homossexualidade crime em Uganda, manifesta que o Código Penal não criminaliza a pessoa, o homossexual, e sim a prática do ato interdito; (iii) desconsidera a intenção do autor no ato para concluir que, ainda assim, a publicação da identidade de pessoas LGBTI com o chamado para enforcá-los destacou-as dos demais membros da comunidade, colocados como mais dignos ${ }^{19}$. Nesse sentido, afirma que, "se tudo o que uma pessoa merece é a morte, e arbitrariamente, então a dignidade humana dessa pessoa é colocada no mais baixo nível"20.

O debate acerca do projeto de lei, a campanha por sua aprovação, a conclamação a enforcar pessoas LGBTI e a própria decisão da Corte teriam redundado na morte do ativista e advogado da SMUG David Kato, que menos de um mês depois da sentença, em finais de janeiro de 2011, foi atingido na cabeça com duas marteladas, falecendo a cami290 nho do hospital. Oficialmente, negou-se que o crime guardasse relação com a identidade ou a militância de Kato; em contrapartida, o movimento LGBTI ugandense atribuiu o crime a isso e apontou para a negligência e omissão da polícia na condução de investigações, a qual concluiu que pode ter se tratado de crime passional ${ }^{21}$. O caso gerou clamor internacional e a morte de Kato foi oficiosamente atribuída à sua identidade gay e militância, em jornais, programas de tevê, vídeos e filme de circulação global ${ }^{22}$. De todo

\footnotetext{
${ }^{19}$ Ver Ação: "Kasha Jacqueline, David Kato Kisuule, and Onziema Patience v. Rolling Stone Ltd. and Gilles Muhame”, The High Court of Uganda, Miscellaneous cause, n. 163, 2010, pp. 8-9.

${ }^{20}$ No original: "If a person is only worthy of death, and arbitrarily, then that person's human dignity is placed at the lowest ebb". Ver nota de rodapé 19, "Ação: Kasha Jacqueline...", p. 9.

${ }^{21}$ Entrevista concedida pelo presidente de Uganda, Y. Museveni, a C. Amanpour, CNN, em 19 abr. 2012.

${ }^{22}$ Ver, por exemplo, a matéria escrita por Xan Rice poucos dias após a morte de Kato, "Ugandan's 'hang them' paper has no regrets after David Kato's death", The Guardian, 27 Jan. 2011.
} 
modo, e como já tinha acontecido na esteira da causa ganha pelo movimento LGBTI ugandense em 2008, a decisão de 2010 teria importado em novo recrudescimento do ativismo anti-LGBTI, com manifestações frequentes de autoridades religiosas e missionários, parlamentares e ministros ugandenses.

Esse recrudescimento do ativismo anti-LGBTI em Uganda teria implicado, ao seu turno, o isolamento no âmbito interno e mesmo o refúgio de ativistas ugandenses, sobretudo na Holanda, Inglaterra e Estados Unidos. Daí eles puderam, ao menos, dar prosseguimento à sua campanha, com foco em impedir que o projeto de lei anti-homossexualidade, em torno do qual se reabriu o debate em 2011 e que seria reapresentado por Bahati em 2012, de fato se tornasse lei. Nesse período, atuaram junto aos ativistas pró-LGBTI que permaneceram em Uganda, em ONGs internacionais e independentemente, publicando colunas em jornais como o Huffington Post, artigos casuais em The Guardian e New York Times, concedendo entrevistas a uma gama de emissoras que se estende da CNN à al Jazeera, trazendo compatriotas praticamente isolados em Uganda para falar no Ocidente desenvolvido, em especial, nos Estados Unidos. Até finais de 2013, seu "cosmopolitismo enraizado", para falar com Tarrow, foi suficiente para barrar a aprovação do projeto, agora modificado, tendo dispensado a pena capital para a forma agravada de homossexualidade.

No período de 2010 a 2013, testemunharam-se desdobramentos importantes em matéria de direitos de LGBTI no plano global, com o Comentário Geral adotado pelo Conselho de Direitos Humanos da ONU incluindo expressamente a orientação sexual entre as bases pelas quais se condena a discriminação e sua Resolução 17/19. Em torno dos direitos dessa minoria em Uganda, torna-se mais corrente falar que a homossexualidade é "não africana", "não natural", "não de Deus", "pecado" e, principalmente, que 
"a homossexualidade não é um direito humano"23. Por outro lado, torna-se também mais comum falar que as pessoas LGBTI eram "perseguidas" em Uganda, que havia uma "perseguição" em curso, que a homofobia tinha se tornado uma "perseguição" depois da apresentação do polêmico projeto de lei ${ }^{24}$. Esse enquadramento da situação pelos militantes LGBTI passou a ter, no período, maior consequência prática por força da resolução do Conselho de Direitos Humanos, que recomenda que a "perseguição com base em orientação sexual” seja considerada para fins de concessão de asilo ${ }^{25}$.

Ele se mostra importante, ademais, para o acionamento da Corte distrital do Distrito de Massachusetts pela SMUG contra Scott Lively, ainda em 2013, com fundamento no Alien Tort Statute, ou Alien Tort $\mathrm{Act}^{26}$, e sob a alegação de que Lively tinha papel crucial numa perseguição generalizada e sistemática de LGBTI em Uganda. Em peça inicial, a 292 SMUG cuida de nomear os principais atores da rede transnacional anti-LGBTI que atuou em Uganda, especificando pessoas e ONGs, como Martin Ssempa, atuante em Uganda,

\footnotetext{
${ }^{23}$ Entrevistas concedidas por J. N. Buturo em reportagem de 2010 sobre gays em Uganda para a BBC, em 4 jul. 2010, e por D. Bahati a Arwa Damon, CNN, em 5 jan. 2014.

${ }^{24}$ Entrevistas concedidas em Uganda por Godfrey Odongo, em nome da Anistia Internacional - Uganda, bem como pelos ativistas Frank Mugisha, Dennis e Bob em reportagem de 2010 sobre gays em Uganda para a BBC, em 4 jul. 2010. Odongo entende que a propositura de um projeto dedicado a reprimir LGBTI num país com tantos problemas econômicos, políticos e sociais a enfrentar daria mostras de que há, sim, uma perseguição em curso. Já o ativista Dennis afirma que, independentemente da aprovação do projeto no Parlamento, sua simples propositura causaria uma escalada da violência contra LGBTI, porque, se não aprovado, as pessoas tomariam em suas mãos a realização dos seus desígnios. Nesse mesmo sentido falou Kato, em depoimento reproduzido no filme God loves Uganda, ressaltando que a lista de "top homos" ugandenses tinha vindo a público numa sociedade em que se faz justiça com as próprias mãos.

${ }^{25}$ Ver: UNHCR, Guidance note on refugee claims relating to sexual orientation and gender identity, p. 3.

${ }^{26}$ Nos termos do 28 U.S. Code 1350, "the district courts shall have original jurisdiction of any civil action by an alien for a tort only, committed in violation of the law of nations or a treaty of the United States".
} 
especialmente junto a universitários, Stephen Langa, James Buturo, David Bahati, a Family Life Network, a Exodus Internacional. Também detalha suas ações e as situa no tempo, dando consistência ao enquadramento pretendido: a perseguição sistemática e generalizada, a ponto de configurar um crime contra a humanidade ${ }^{27}$.

Em decisão de 14 de agosto de 2013 afastando o pedido de recusa da ação, a Corte aceita o enquadramento proposto pela SMUG, declarando que os atos inicialmente alegados configuram uma perseguição generalizada e sistemática com base na orientação sexual e, como tal, crime contra a humanidade. Com isso, Lively responderia por ajudar ou incitar a violação de norma internacional tão séria quanto era a pirataria na época da consagração do estatuto. $\mathrm{Na}$ decisão, a Corte distingue "discriminação", "perseguição" e "crime contra a humanidade", no caso, a perseguição como crime contra a humanidade. Ela sustenta que a primeira é definida por um Comentário Geral do Conselho de Direitos Humanos de 1989, enquanto a segunda e a terceira são definidas pelo Estatuto do Tribunal Penal Internacional (TPI), portanto, criminalmente reguladas, encerrando, ambas, uma conduta discriminatória, distinguindo-se da discriminação pela intensidade e distinguindo-se uma da outra por ser a perseguição como crime contra a humanidade generalizada ou sistemática ${ }^{28}$. Um ponto comum a todas - discriminação, perseguição e perseguição como crime contra a humanidade - é que a orientação sexual não figura entre as causas pelas quais se interdita a discriminação. Esse silêncio das normas internacionais não chega a ser, porém, um problema para a Corte, que pondera que a cláusula de salva-

\footnotetext{
${ }^{27}$ Ver Ação "Sexual Minorities Uganda v. Scott Lively", United States District Court, District of Massachusetts, July 13, 2012.

${ }^{28}$ Ver Ação "Sexual Minorities Uganda v. Scott Lively", Memorandum and Order regarding Defendant's Motions to Dismiss, United States District Court, District of Massachusetts, Aug. 14, 2013, pp. 21-26.
} 
guarda contida nessas normas dá abrigo a qualquer grupo tomado como alvo ${ }^{29}$.

O recurso ao Judiciário norte-americano pode ser entendido em relação com a escalada da repressão social e institucional a pessoas LGBTI em Uganda, do bloqueio dos canais internos de diálogo e negociação, evidenciado pela ausência de efetividade das decisões judiciais pró-LGBTI, da estrutura internacional de oportunidade, em que Uganda não poderia acionar o sistema regional de direitos humanos e não conta com uma instância judicial global dedicada à matéria. Ele mostra que a abertura da estrutura internacional de oportunidade não precisa ser intergovernamental, mesmo no caso de mobilização legal ${ }^{30}$ : no caso, ela é dada pela estrutura doméstica de outro Estado. Mas ela é dada e "criada", ao mesmo tempo, pelo enquadramento da campanha anti-LGBTI em Uganda como crime contra a humanidade, uma vez que, a julgar pelo que disse a própria Corte, a situação estaria fora da 294 sua jurisdição se não fosse esse enquadramento. Por fim, na "criação" dessa oportunidade, não se pode desconsiderar a sensibilidade ao problema nos Estados Unidos, onde, menos de um mês antes, a Suprema Corte tinha apreciado dois casos paradigmáticos de direitos de pessoas LGBTI, United States v. Windsor e Hollingsworth v. Perry, com decisão favorável a essa minoria em ambos.

\section{Limites da abordagem teórica de Keck e Sikkink e potenciais caminhos a seguir}

Não obstante todos esses esforços, em dezembro de 2013 o projeto de lei, pendente de votação desde 2012, foi aprova-

\footnotetext{
${ }^{29}$ Ver Ação "Sexual Minorities Uganda v. Scott Lively", Memorandum and Order..., Aug. 14, 2013, p. 26.

${ }^{30}$ No caso de Uganda, isso seria dificultado pela inexistência de uma corte global de direitos humanos e pelo fato de que a prática de atos homossexuais configura crime em 38 de 56 países africanos desde os tempos coloniais, donde também não seria acionado o sistema africano.
} 
do pelo Parlamento de Uganda e, após alguma hesitação, sancionado pelo presidente Museveni, em janeiro de 2014. Tendo em conta o modelo do "efeito bumerangue", esse desfecho não deixa de surpreender.

Em cerca de dez anos, o movimento LGBTI ugandense e a rede transnacional que ele passou a formar em meados dos anos 2000 acumularam vitórias judiciais importantes no plano nacional, abriram espaço na estrutura internacional mediante mobilização legal e angariaram apoio social, político e mesmo institucional, sobretudo nos Estados Unidos e na Europa. Tanto os governos que poderiam pressionar o governo ugandense como o próprio governo de Uganda tinham algum tipo de vulnerabilidade - social, no caso dos primeiros; material, no caso do segundo -, e essa vulnerabilidade foi percebida e explorada pelos ativistas, tendo os Estados Unidos e países europeus se empenhado em pressionar o governo ugandense. Por fim, ela teria sido bem-sucedida em construir a minoria LGBTI ugandense como vulnerável e mobilizou quadros, ou frames, de grande ressonância, como "igualdade perante a lei", "não discriminação" e a "perseguição como crimes contra a humanidade", sendo esses crimes comumente usados para designar as mais graves violações de direitos humanos.

Keck e Sikkink parecem não contemplar, entretanto, a possibilidade de que uma campanha, em regra com finalidade pontual, altere as condições em que o processo político se desenrola a partir dela, caso ela não sele a disputa. No caso de Uganda, essa negligência implica desconsiderar que a campanha contra o projeto de lei possa ter facilitado a cooptação dos "direitos de LGBTI" por um discurso "anti-imperialista"31, explorando uma associação entre "direitos humanos" e "imperialismo" construída por regimes autoritários nos anos 1960 e 1970. Nesse sentido, Bahati, Buturo

\footnotetext{
${ }^{31}$ Este é o argumento central do estudo de Kaoma (2009).
} 
e o presidente Museveni falam abertamente em "imperialismo social" tanto de Estados do Ocidente desenvolvido como de organizações internacionais, como a ONU, o Banco Mundial. Não seria, pois, casual a fala de Bahati, Buturo e de cidadãos comuns de que "não há um direito humano à homossexualidade" e de que a lei recentemente sancionada protege os valores, as crenças, as tradições, a família e as crianças ugandenses. Também não seria casual a sincronia entre os avanços na agenda LGBTI nos Estados Unidos e o recrudescimento da homofobia e repressão estatal ao grupo em Uganda.

Nesse ponto, depara-se com limitações na abordagem de Keck e Sikkink, decorrentes da literatura sobre frames em geral, que não analisa nem o sentido dos quadros nem o discurso em que eles aparecem na mobilização social. Em resposta a essa crítica, se poderia afirmar que a abordagem trabalha com a ideia de que os frames são usados 296 numa retórica, e não soltos; mas, de todo modo, as abordagens teóricas não tomam essa retórica como elemento de análise, nem consideram a possibilidade de que ela tenha impacto alhures. Essa discussão tem importância porque, como fica claro no caso, o discurso de denominações cristãs teria sido apropriado pela rede anti-LGBTI atuante em Uganda, tendo impacto maior do que a circulação de frames; em contrapartida, os direitos humanos, tomados como frame e como discurso, podem ter parecido uma via bloqueada aos ativistas LGBTI em Uganda. E em que medida os quadros invocados por eles - "não discriminação" e "igualdade legal" - teriam sustentação fora do discurso dos direitos humanos, ainda mais estando em questão a inclusão dos que estão à margem da construção social do humano?

Um desafio de ordem teórica posto pelo estudo da disputa em torno dos direitos da minoria LGBTI em Uganda seria, pois, conferir relevância analítica ao discurso, sem, com 
isso, tornar a abordagem de Keck e Sikkink inconsistente. Um caminho seria seguir a opção de Sally Engle Merry (2006) e trabalhar com a noção de "repertório", entendido como "criações culturais aprendidas" que emergem a partir da luta política, constrangem os atores, mas também estão sujeitas às suas interações, apresentando, pois, uma dimensão dialógica ${ }^{32}$. Essa opção possibilita incorporar ao estudo das redes transnacionais de advocacy o elemento do discurso, que, no caso de Uganda, mostrou-se fundamental na prática dos direitos humanos e limitado pela abordagem centrada nos frames. Tal opção também oferece a vantagem de propiciar à abordagem de Keck e Sikkink um ganho analítico sem acarretar-lhe perda em consistência, dado que ela não se afastaria da matriz da teoria do processo político, sobre a qual Keck e Sikkink, afinal, elaboram. Mais do que isso, para Engle Merry, esse deslocamento importaria num ganho analítico em sensibilidade aos constrangimentos do próprio campo discursivo, em decorrência da assimetria de poder. De sorte que, se articulada ou em diálogo com a proposta da autora, a abordagem de Keck e Sikkink ainda contornaria a crítica que lhe é mais comumente dirigida, a de ignorar a desigualdade de poder entre os atores. Por outro lado, reconhece-se que ela pode colocar dificuldades de ordem metodológica, por implicar atenção ao sentido, não só à moldura, e, em consequência disso, que se atente para a tradução, para o ato e as necessidades da tradução, nos locais do transnacional.

Outro aspecto do caso do qual a abordagem proposta por Keck e Sikkink pode ser complementada é o papel dos tribunais no processo político em que se engajaram redes pró e anti-LGBTI. Como se disse, cada decisão judicial

\footnotetext{
${ }^{32}$ Nos termos de Tilly (1995; tradução da autora),"repertórios são criações culturais aprendidas, mas eles não descendem de filosofia abstrata ou tomam forma como um resultado de propaganda política; eles emergem na luta". Ver também Steinberg (1999, pp. 736-80).
} 
proferida pela mais Alta Corte de Uganda em prol de LGBTI ugandenses parece ter ocasionado uma escalada da repressão social e político-institucional a pessoas e ao ativismo LGBTI no país, de acordo com relatos de ativistas ugandenses em vídeos. Segundo a rede pró-LGBTI e a primeira manifestação da Corte distrital norte-americana, o processo político em Uganda teria se tornado uma perseguição generalizada e sistemática, a ponto de configurar crime contra a humanidade. Como crime contra a humanidade, essa perseguição poderia ter sido levada ao Tribunal Penal Internacional (TPI), em que, por sinal, outros ugandenses são acusados de crimes de guerra e crimes contra a humanidade. É certo que ONGs não têm capacidade de agir, não podem propor uma ação ao TPI, mas o procurador do Tribunal poderia requerer autorização para investigar a situação em Uganda. Como explicar o recurso à Corte distrital norte-americana, com fundamento no Alien Torts Act, nos limi298 tes do que propõem Keck e Sikkink?

De novo, a incorporação da análise do discurso pode representar um ganho importante para a discussão elaborada pelas autoras. No caso, essa incorporação pode ser mediada, por exemplo, pela proposta de Upendra Baxi (2006, p. 169) de abordar a legalização dos direitos humanos a partir da leitura e escritura, da política de produção e produção da política de direitos humanos. Baxi propõe tomar o texto das normas jurídicas como um fato social-institucional, uma produção cultural, resultante de um acordo representado numa linguagem e, nessa medida, dependente de crenças e outros elementos dessa ordem. Por isso, um texto interage com outros textos e deve-se buscar compreendê-lo em relação com esses outros textos, bem como com a sociedade e a história. Segundo Baxi (2006, pp. 172 e ss.), qualquer significado que o texto possa ter emanaria da estrutura e da contestação dos significados consubstanciados no próprio texto. 
Lendo assim a decisão da corte distrital, pode-se notar que ela se baseia em normas internacionais, principalmente no Estatuto do TPI. Não cita, porém, qualquer decisão de corte ou tribunal internacional em linha com seu entendimento e, na passagem em que cita a jurisprudência internacional, recorre a uma decisão sobre discriminação por raça. Mas quando se lê o próprio Estatuto do TPI, não só a orientação sexual não figura entre as razões pelas quais se interdita discriminar ou perseguir, mas lê-se que "gênero" refere a dois "sexos", ao masculino e ao feminino, no contexto da sociedade, não podendo ter qualquer significado $^{33}$. Uma leitura do texto ou do contexto normativo não autoriza inferir daí que a perseguição generalizada ou sistemática contra LGBTI seja autorizada pelo Estatuto; porém, uma leitura que considere o texto e o contexto normativo, a história e o contexto social, implica que, segundo ele, tal perseguição não configura crime contra a humanidade.

Buscando as escolhas que a norma encerra, também se pode entender que, na medida em que uma perseguição generalizada ou sistemática por raça ou gênero, entre outras, configura crime contra a humanidade, uma perseguição desse tipo, generalizada ou sistemática, por orientação sexual não merece a mesma condenação por parte dos autores do Estatuto: esse teria sido o acordo a que se chegou a esse respeito. Os limites desse acordo não impediram, contudo, que, na prática dos direitos humanos, a rede pró-LGBTI atuante em Uganda extrapolasse os limites da norma efetuando dela uma leitura dirigida por sua atuação política e, extrapolando o argumento do próprio Baxi, participasse na sua reescritura, com aquela primeira decisão da corte distrital. Nesse processo, os crimes contra a humanidade, escritos em autoria diplomática coletiva, podem, por-

\footnotetext{
${ }^{33}$ Art. 7 (3). For the purpose of this Statute, it is understood that the term "gender" refers to the two sexes, male and female, within the context of society. The term "gender" does not indicate any meaning different from the above.
} 
tanto, ter sido desconstruídos pelos ativistas LGBTI atuantes em Uganda e reconstruídos ao serem reescritos na decisão da Corte distrital, à revelia da atual dominação da rede anti-LGBTI em Uganda.

\section{$* * *$}

Neste artigo, trabalhou-se a disputa em torno dos direitos de LGBTI em Uganda a partir da abordagem teórica de Keck e Sikkink para o estudo de redes transnacionais de advocacy, com foco no modelo do "efeito bumerangue". Depois de construir a disputa política acerca dos direitos de LGBTI em Uganda como um caso de disputa política entre duas redes dessa ordem, procurou-se indicar limites da abordagem em confronto com um caso difícil. Dois limites foram identificados. Primeiro deles: a negligência do sentido de figuras de linguagem empregadas na ação 300 política e do discurso em que elas aparecem. E o segundo: o papel indiferenciado das normas jurídicas e cortes ou tribunais internacionais em relação a normas sociais e ao espaço político.

Entendeu-se, no artigo, que a aposta de Merry em trabalhar com "repertório", em lugar de frame, pode permitir contornar algumas limitações do potencial da abordagem de Keck e Sikkink, com o ganho da incorporação do discurso como elemento e do sentido como dimensão analítica, sem comprometer-lhe a consistência. No que se refere ao segundo limite, entende-se que a proposta de Baxi de abordar a legalização dos direitos humanos na chave política de produção-produção de política pode elucidar o recurso da rede pró-LGBTI ao Judiciário norte-americano. Iluminado pela proposta de Baxi, esse recurso da rede pode extrapolar os limites da própria proposta e dar mostras de que, na produção de política pela leitura, há reescritura dos direitos humanos. 


\section{Renata Reverendo Vidal K. Nagamine}

é mestre e doutoranda em Direito Internacional pela Faculdade de Direito da USP.

\section{Bibliografia}

BAHATI, H. D. 2009. "The Anti-Homosexuality Bill, 2009”. Bills Suplement, n. 13, Sept. 25.

BAXI, U. 2006. "Politics of reading human rights: inclusion and exclusion withing the production of human rights", In: MECKLED-GARCÍA, S.; CALI, B. The legalization of human rights: multidisciplinary perspectives on human rights and human rights law. London, New York: Routledge. [Versão kindle]

EDWARDS, J. 2010. "Bahati: The unlikely gay basher". The Independent Uganda, Jan. 13.

ENDING “don't ask, don't tell”. 2010. New York Times, Jan. 29.

GAY STOLBERG, S. 2009. "Obama invites gay rights advocates to White House". New York Times, June 22.

HULSE, C. 2009. "House votes to expand hate crimes definition". New York Times, Oct. 9.

KAOMA, K. 2009. "Globalizing the culture wars: U.S. conservatives, African churches, and homophobia”. Political Research Associates. KHAGRAM, S.; RIKER, J. V.; SIKKINK, K. 2002a. "From Santiago to Seattle: transnational advocacy groups restructuring world politics". In: KHAGRAM, S.; RIKER, J. V.; SIKKINK, K. (orgs.) Restructuring world politics: transnational social movements, networks, and norms. Minneapolis: University of Minnesota Press.

KHAGRAM, S.; RIKER, J. V.; SIKKINK, K. 2002b. Restructuring world politics: transnational social movements, networks, and norms. Minneapolis: University of Minnesota Press.

KECK, M. E.; SIKKINK, K. 1998. Activists beyond borders: advocacy networks in international politics. Ithaca: Cornell University Press.

McNEIL JR., D. G. 1998. "Harare Journal; Mugabe attacks, and gay Zimbabweans fight back”. New York Times, July 14.

MERRY, S. E. 2006. "Transnational human rights and local activism: Mapping the Middle”, American Anthropologist, v. 108, n. 1, pp. 38-51. MIWAMBO, N. 2010. "Are gays more powerful than Uganda opposition?". The Independent Uganda, March 9.

NAGOURNEY, A. 2009. "Political shifts on gay rights lag behind culture". New York Times, June 28. 
RICH, F. 2009. "40 years later, still second class Americans". New York Times, June 28.

SEELYE, K. Q. 2010. "Marriage Law is challenged as equaling discrimination". New York Times, May 6.

SNOW, D. A.; BENFORD, R. D. 1998. "Ideology, frame resonance, and participant mobilization". In: KLANDERMANS, B.; KRIESI, H.; TARROW, S. (orgs.). International social movement research. Vol. 1, Greenwich: JAI Press.

STEINBERG, M. W. 1999. "The talk and back talk of collective action: a dialogic analysis of repertoires of discourse among nineteenth century English cotton spinners". American Journal of Sociology, v. 105, n. 3, pp. 736-80.

TARROW, S. 1996. "State and opportunities: the political structuring of social movements”. In: McADAM, D.; McCARTHY, J.; ZALD, M. N. (orgs.). Comparative perspectives on social movements: political opportunities, mobilizing structures, and cultural framings. Cambridge: Cambridge University Press.

TILLY, C. 1995. “Contentious Repertoires in Great Britain, 1758-1834”. In: TRAUGOTT, M. (org.). Repertoires and Cycles of Collective Action. Durham, N.C.: Duke University Press.

302 UWIHANGANYE, A. 2010. "Conservatism blocking dynamic thinking in Africa”. The Independent, Uganda, Jan. 6. 


\section{OS DIREITOS DE PESSOAS LGBTI EM UGANDA: REDES TRANSNACIONAIS DE ADVOCACYE A LEI ANTI- HOMOSSEXUALIDADE}

\section{RENATA REVERENDO VIDAL K. NAGAMINE}

Resumo: Este artigo trata da disputa em torno dos direitos de pessoas LGBTI em Uganda, envolvendo duas redes transnacionais de advocacy dos anos 1990 à aprovação da mundialmente conhecida "lei anti-homossexualidade" ugandense. Elaborando sobre o clássico estudo de M. Keck e K. Sikkink sobre redes transnacionais de advocacy, o artigo busca identificar os principais atores nas redes, a mudança de escala na rede em prol dos direitos de pessoas LGBTI, suas estratégias, seus alvos e os frames que elas mobilizam. Finalmente, o texto indica limites da abordagem teórica de Keck e Sikkink e possíveis abordagens complementares.

Palavras-chave: LGBTI; Redes Transnacionais de Advocacy; Uganda; Ativismo Transnacional; Direitos Humanos; Efeito Bumerangue.

\section{LGBTI PEOPLE'S RIGHTS IN UGANDA: TRANSNATIONAL ADVO- CACY NETWORKS AND THE ANTI-HOMOSEXUALITY ACT}

Abstract: This article concerns the struggle between two transnational advocacy networks about LGBTI people's rights in Uganda from the mid 1990s to the approval of the Ugandan "anti-homosexuality legislation”. Drawing upon M. Keck and K. Sikkink's classical study on transnational advocacy networks, the article identifies the main actors in both networks, the scale shift in the pro-LGBTI people's rights one, their strategies, their targets, and the frames they mobilize. Finally, it indicates possible limits of Keck and Sikkink's theoretical framework, and it suggests some possible complementary approaches.

Keywords: LGBTI; Transnational Advocacy Networks; Uganda; Transnational Activism; Human Rights; Boomerang Effect. 